\title{
MEMS-Based Reflective Intensity-Modulated Fiber-Optic Sensor for Pressure Measurements
}

\author{
Ning Zhou ${ }^{\circ}$, Pinggang Jia *, Jia Liu ${ }^{\circledR}$, Qianyu Ren, Guowen An, Ting Liang and Jijun Xiong \\ Science and Technology on Electronic Test and Measurement Laboratory, North University of China, \\ Taiyuan 030051, China; zhouningnuc@163.com (N.Z.); 18734920710@163.com (J.L.); \\ renqianyu1315@126.com (Q.R.); anguowen@nuc.edu.cn (G.A.); liangtingnuc@nuc.edu.cn (T.L.); \\ xiongjijun@nuc.edu.cn (J.X.) \\ * Correspondence: pgjia@nuc.edu.cn; Tel.: +86-351-3925-088
}

Received: 10 March 2020; Accepted: 10 April 2020; Published: 15 April 2020

\begin{abstract}
A reflective intensity-modulated fiber-optic sensor based on microelectromechanical systems (MEMS) for pressure measurements is proposed and experimentally demonstrated. The sensor consists of two multimode optical fibers with a spherical end, a quartz tube with dual holes, a silicon sensitive diaphragm, and a high borosilicate glass substrate (HBGS). The integrated sensor has a high sensitivity due to the MEMS technique and the spherical end of the fiber. The results show that the sensor achieves a pressure sensitivity of approximately $0.139 \mathrm{mV} / \mathrm{kPa}$. The temperature coefficient of the proposed sensor is about $0.87 \mathrm{mV} /{ }^{\circ} \mathrm{C}$ over the range of $20^{\circ} \mathrm{C}$ to $150{ }^{\circ} \mathrm{C}$. Furthermore, due to the intensity mechanism, the sensor has a relatively simple demodulation system and can respond to high-frequency pressure in real time. The dynamic response of the sensor was verified in a $1 \mathrm{kHz}$ sinusoidal pressure environment at room temperature.
\end{abstract}

Keywords: fiber-optic; reflective intensity modulated; MEMS; gas pressure sensor

\section{Introduction}

Pressure measurement in harsh environments is of great value in various fields, such as oil logging, aerospace vehicle engine testing, and in the pharmaceutical industry [1-3]. At present, pressure sensors used in engineering mainly include piezoresistive pressure sensors, piezoelectric pressure sensors, capacitive pressure sensors, and fiber optic pressure sensors [4-7]. Compared with the electrical sensor, the fiber optic sensor has unique advantages. Fiber optic sensors are more adaptable to harsh environments, more resistant to electromagnetic interference, and have compact size and simple structure [8]. Until now, fiber-optic pressure sensors have been developed into many subtypes according to the working mechanism, including modulating intensity [9,10], frequency [11], phase [12], wavelength [13], and polarization [14].

In recent years, intensity-modulated fiber-optic sensors have attracted significant interest due to their simple system, low cost, and high dynamic response. Shen et al. proposed a fiber-optic displacement sensor, which is based on reflective intensity modulation using a fiber-optic collimator [15]. Vallan et al. utilized a low-cost plastic fiber-optic sensor for displacement and acceleration sensing, and verified it under the actual conditions of a sinusoidal vibration [16]. Perrone et al. reported a novel non-contact method to measure vibrations, which enabled a submicron resolution [17]. Cui et al. designed a new dual fiber structure sensor based on a fiber Bragg grating probe that can measure the axial and radial contact displacement simultaneously and can be used to measure the shape change of the fuel nozzle in engines [18]. Vallan et al. proposed and analyzed an intensity-modulated sensor for 2D crack monitoring [19]. Guermat et al. presented a fiber-optic sensor that could monitor the temperature and pressure. The measurements were taken by a reflectometer [20]. Due to the limitations of temperature- 
resistant materials and the current processing technologies, the above sensors are not suitable for a harsh temperature environment or batch-production.

With the development of technology, a considerable number of methods have been applied to fabricate the fiber-optic sensors [21-23], for example, MEMS, chemical etching, lasing, applying special optical fibers, and so on [24-28]. Ge et al. proposed an optical MEMS pressure sensor based on a mesa-diaphragm structure [29]. Poeggel et al. reported a femtosecond-laser-based inscription technique for post-fiber-Bragg grating inscription in an extrinsic Fabry-Perot interferometer pressure sensor; the sensor has a small size and high stability [30]. Hirsch et al. reported the fiber-optic microsphere sensors, which realized high-sensitivity refractive index detection [31]. The MEMS-based optical fiber pressure sensors have attracted significant interest, as they are quite small and ideal for applications where restricted space or minimal measurement interference is a consideration.

In this study, we proposed a MEMS-based reflective intensity-modulated fiber-optic sensor for pressure measurement. The sensor consists of two multimode optical fibers with a spherical end, a quartz tube with dual holes, a silicon sensitive diaphragm, and a high borosilicate glass substrate (HBGS) integrated by MEMS technique. The sensor was assembled and sealed using a CO2 laser, which is beneficial for improving the sensor performance and avoiding thermal mismatch between the adhesive and the fiber-optic. The temperature features were characterized over the temperature range of $20-150{ }^{\circ} \mathrm{C}$, and the dynamic response was verified at room temperature. The sensitivity of the sensor was significantly improved by fabricating a micro-sphere at the end of the multimode fiber. Due to the intensity mechanism, the sensor has a relatively simple demodulation system and can respond to high frequency pressure. Besides, the pressure sensor proposed in this paper has the potential to be mass-produced, which can reduce manufacturing costs.

\section{Configuration and Operating Principle}

The configuration of the proposed sensor is shown in Figure 1a. The sensor consists of two multimode fibers with a spherical end, a quartz tube with dual holes, and a sensor head. The sensor head structure consisted of an HBGS covered with a silicon sensitive diaphragm. Two multimode optical fibers were inserted inside the quartz tube and further vertically into the sensor head. A pressure cavity was formed between the ending of the optical fiber and the inner surface of the silicon sensitive diaphragm. The sensing principle of pressure is shown in Figure 1b. The light was transmitted in the transmitting fiber and incident on the sensitive diaphragm, then reflected by the surface of the sensitive diaphragm, and received by the receiving fiber. The final reflection spectrum was analyzed by a photodetector. When an external pressure was applied to the sensitive diaphragm, the diaphragm deformed, which induced the optical path change. The output voltage of the photodetector changes linearly with the pressure. By processing the voltage signal by the photodetector, the change in the external pressure can be monitored in real time.

When the light propagates in the transmitting fiber, the radial distribution along the fiber axis can achieve an approximately Gaussian distribution. The irradiance of emitted light from the transmitting fiber obeys an exponential law according to [32-34]:

$$
\mathrm{I}(\mathrm{r}, \mathrm{z})=\frac{2 \mathrm{P}_{0}}{\pi \mathrm{w}^{2}(\mathrm{z})} \mathrm{e}^{\frac{-2 \mathrm{r}^{2}}{\mathrm{w}^{2}(\mathrm{z})}}
$$

where $\mathrm{P}_{0}$ is the optical power sent by the transmitting fiber; $\mathrm{r}$ and $\mathrm{z}$ are the radial coordinates and pressure cavity length, respectively; and $\mathrm{w}(\mathrm{z})$ is waist radius of the reflected light at the sensitive diaphragm and can be defined as:

$$
\mathrm{w}(\mathrm{z})=\mathrm{w}_{0}+2 \mathrm{ztan}(\operatorname{acrsin}(\mathrm{NA}))
$$

where $\mathrm{w}_{0}$ is the radius of the transmitting fiber, and NA is numerical aperture of the transmitting fiber. 
The receiving fiber collects the light reflected from the sensitive diaphragm, and the total received optical power $\left(P_{z}\right)$ can be evaluated by integrating the irradiance $I(r, z)$ within the core region $\left(S_{r}\right)$ of the receiving fiber end:

$$
\mathrm{P}_{\mathrm{z}}=\int_{\mathrm{S}_{\mathrm{r}}} \mathrm{I}(\mathrm{r}, \mathrm{z}) \mathrm{d} \mathrm{S}_{\mathrm{r}}
$$

To better describe the light intensity modulation characteristics of the sensor, the light intensity modulation function (M) is defined as follows:

$$
\mathrm{M}=\frac{\mathrm{P}_{\mathrm{z}}}{\mathrm{P}_{0}}=\mathrm{F}\left(\mathrm{w}_{0}, \mathrm{w}_{\mathrm{r}}, \mathrm{s}, \mathrm{NA}, \mathrm{z}\right),
$$

where $\mathrm{s}$ is center-to-center distance between two fiber cores, and $\mathrm{w}_{\mathrm{r}}$ is the core radius of the receiving fiber. The designed parameters of the proposed fiber-optic pressure sensor obtained by Equation (4) are listed in Table 1.
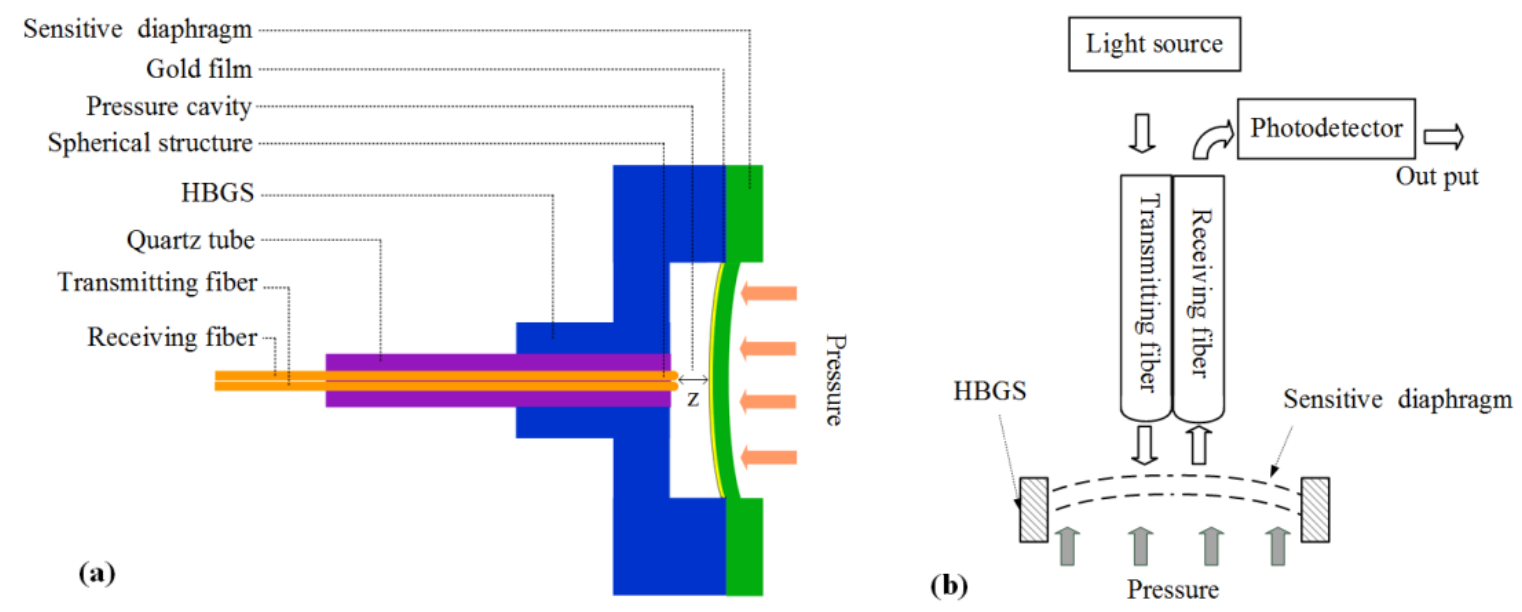

Figure 1. Reflective intensity-modulated fiber-optic pressure sensor: (a) structural configuration; and (b) principle of pressure sensing.

Table 1. Structural parameters of the proposed fiber-optic pressure sensor.

\begin{tabular}{ccc}
\hline Parameter & Symbol & Typical Value $(\mu \mathrm{m})$ \\
\hline Core radius of the transmitting fiber & $\mathrm{w}_{0}$ & 31.25 \\
Core radius of the receiving fiber & $\mathrm{w}_{\mathrm{r}}$ & 31.25 \\
Center-to-center distance between two fiber cores & $\mathrm{s}$ & 150 \\
\hline
\end{tabular}

Compared with the standard fiber, the fiber with microsphere structure has a higher numerical aperture (NA) [35]. The relationship between the NA of the optical fiber and the light intensity is simulated using the MATLAB software, as shown in Figure 2. The initial pressure cavity length of the sensor is $z_{0}\left(z_{0}>s+w_{r}\right)$. In the effective working range [36], the sensor with higher numerical aperture fibers has a larger slope $(k)$ in the intensity modulation function $\left(k_{n_{3}}>k_{n_{2}}>k_{n_{1}}>k_{n_{0}}\right)$. Thus, by using the fiber with a microspherical end, the pressure sensitivity of the sensor could be effectively improved. 


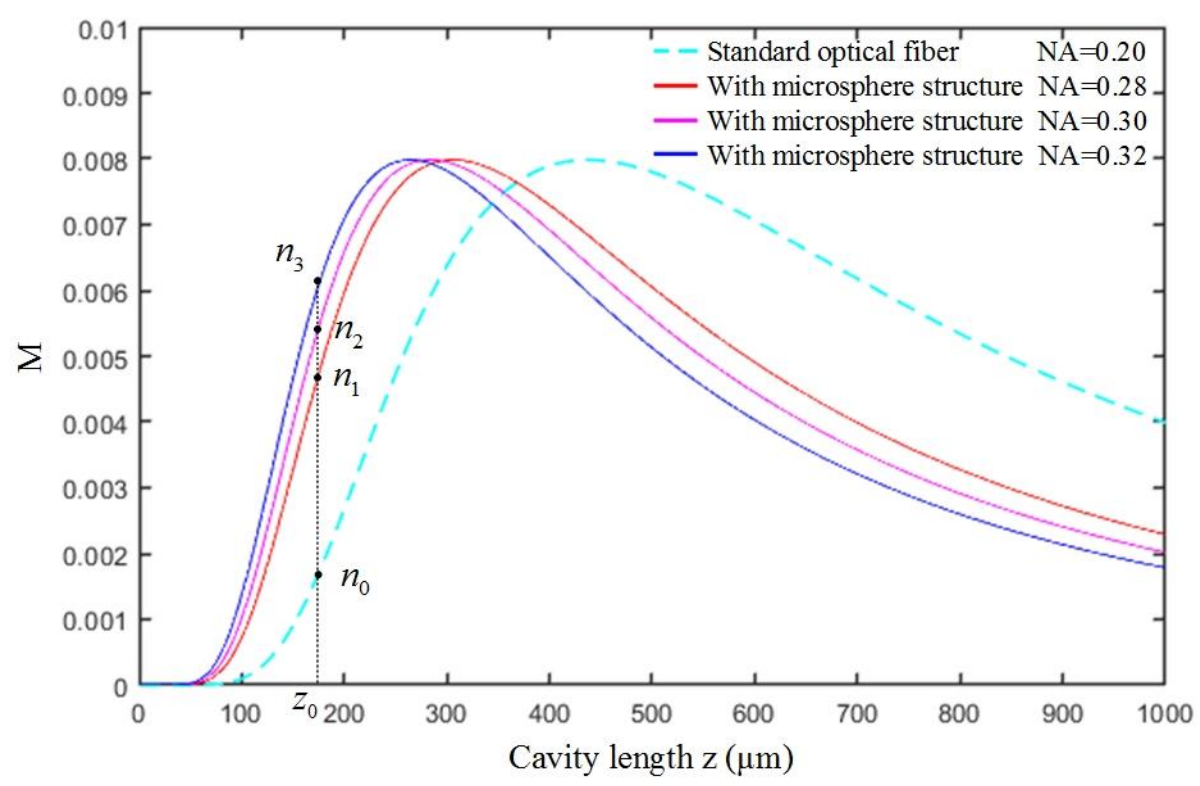

Figure 2. Influence of the numerical aperture on the modulation characteristic curve.

\section{Fabrication of the Sensor}

A 4-inch double-side polished silicon wafer was used to manufacture the sensitive diaphragm. The HBGS was made by a 4-inch high borosilicate glass. The thicknesses of the silicon and high borosilicate glass were $300 \mu \mathrm{m}$ and $2 \mathrm{~mm}$, respectively. The whole manufacturing process mainly included silicon sensitive diaphragm processing, HBGS processing, sensor head assembly, and fiber integration. The fabrication process is as follows: Firstly, a mask layer of the photoresist was coated on one side of each silicon wafer. Secondly, the silicon wafer was subjected to standard lithographic processes using a pattern with a diameter of $3 \mathrm{~mm}$. After this, dry etching was applied to form a deep cylindrical cavity with a diameter of $1.5 \mathrm{~mm}$ and a depth of $210 \mu \mathrm{m}$, as shown in Figure 3a-c. The diaphragm, with a final thickness of approximately $90 \mu \mathrm{m}$, can enhance the pressure sensitivity. Subsequently, the photoresist was repeatedly applied on the back surface, and a second photolithography process was operated to form a back pattern with a diameter of $3 \mathrm{~mm}$. Then, a gold film was formed on the silicon wafer using the magnetron sputtering technique, and the rest photoresist was removed. The silicon sensitive diaphragm was made by using the above steps, as shown in Figure $3 d-g$. Due to the high reflectivity of $\mathrm{Au}$, the optical coupling efficiency of the sensor can be improved.

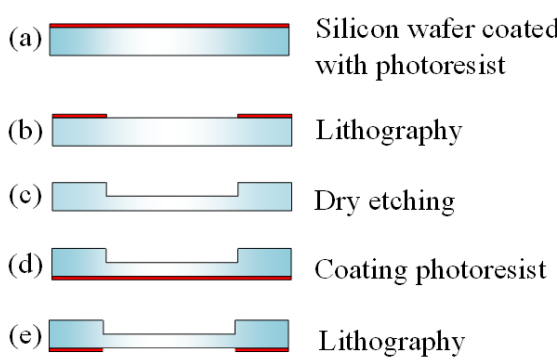

Photoresist

Silicon wafer

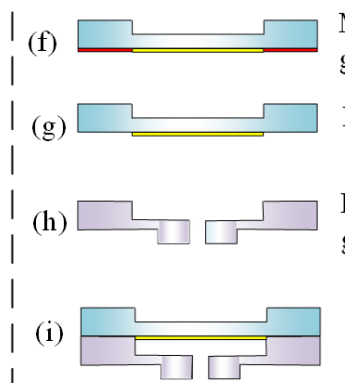

Magnetron sputtering gold film

Remove photoresist

High borosilicate glass substrate

Anodic bonding

(j) Fiber integration
- CO2 laser fusion point

$\square \quad$ Quartz glass Optical fiber

Figure 3. Manufacturing of fiber-optic pressure sensors using MEMS technology. 
After this, a micro-machining method was used to fabricate a cylindrical deep cavity with a diameter of $3 \mathrm{~mm}$ and a depth of $0.3 \mathrm{~mm}$ on one side of a high borosilicate glass. On the other side of the high borosilicate glass, a convex platform with an outer diameter of $2 \mathrm{~mm}$ and a height of $1 \mathrm{~mm}$ was processed. A 1mm-diameter hole was machined at the center of the entire structure. The HBGS could be successfully processed, as shown in Figure 3h. The HBGS was then anodically bonded with the silicon sensitive diaphragm. Then, the entire sensor head was assembled by using the above steps, as shown Figure 3i. For the fiber integration, we inserted two multimode fibers (MMF125/62.5, YOFC, Wuhan, China) with the microsphere end into a quartz tube. We then inserted the entire tube into the sensor head vertically. The microsphere structure was made by laser heating at the end of the fiber. The carbon dioxide laser fusion splicer (LZM-110, Fujikura, Ltd., Tokyo, Japan) was used in the production process. The laser power was 175 bits (about $5.2 \mathrm{~W}$ ), the laser heating time was $2 \mathrm{~s}$, and the heating was performed twice [37]. The sensor was assembled and sealed by using CO2 laser, which was beneficial for improving the sensor performance and avoiding thermal mismatch between the adhesive and the fiber-optic [38], as shown Figure 3j. The length of the initial pressure cavity is $190 \mu \mathrm{m}$.

The entire pressure sensor was $5.0 \mathrm{~mm}$ in length, $5.0 \mathrm{~mm}$ in width, and $1.3 \mathrm{~mm}$ in height, as shown in Figure 4. Figure 4a shows the real image of the sensor. The microsphere end of the fiber was observed under a microscope, as shown in Figure $4 \mathrm{~b}, \mathrm{c}$. Figure $4 \mathrm{~d}$ provides a sectional view of the double-hole quartz casing with an outer diameter of approximately $1 \mathrm{~mm}$ and an aperture of approximately $126 \mu \mathrm{m}$.

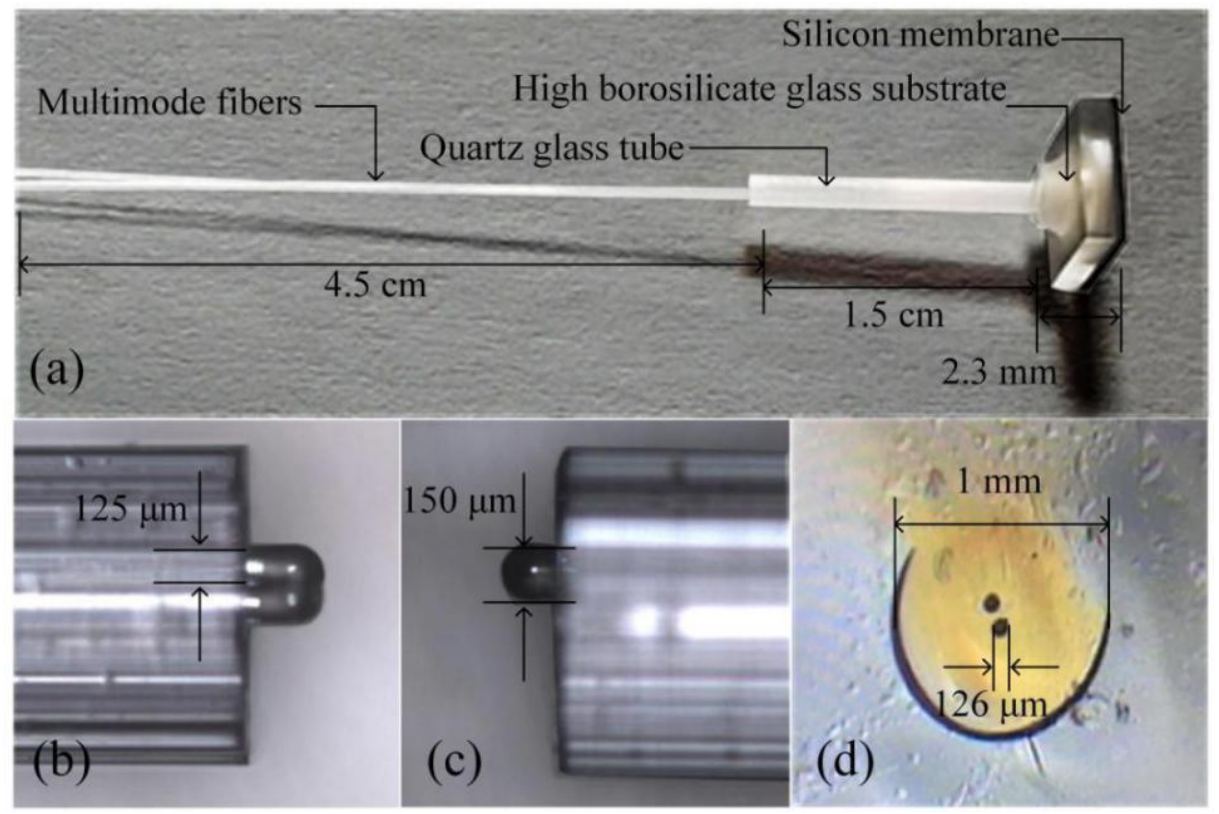

Figure 4. Sensor structure: (a) physical drawing of proposed sensor; (b) microscopic top view of the microsphere end of optical fiber; (c) side view of the optical fiber; and (d) sectional view of the doublehole quartz casing.

\section{Experimental Results}

The experimental setup of the sensor for pressure testing under the dynamic temperature is shown in Figure 5, which includes the fiber sensing system and the temperature and pressure control system. The fiber sensing system consisted of a LED light source (850 T, Wyoptics, Shanghai, China), a fiber optics coupler (WLF $1 \times 2 \mathrm{MM}$ ratio 50:50, 850nm, HJGTEK, Shenzhen, China), a photodetector (New Focus Model 2001, New Port, California, America), and an oscilloscope (TBS 1102, Tektronix, America). The photodetector was set as Gain knob: $10^{4}$, Gain multiplier: 3, and Response factor: 0.36 . The temperature and pressure control system includes a thermal chamber, a pressure vessel, a gas cylinder, a temperature, and pressure controller. 


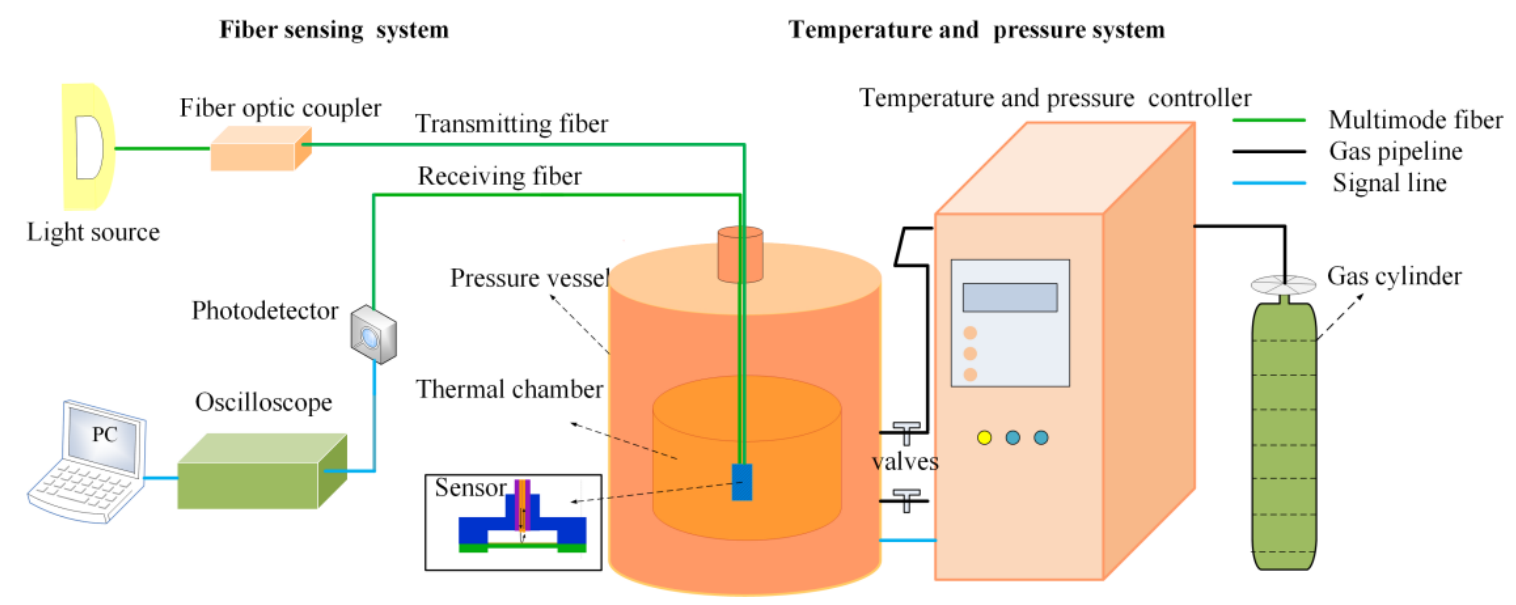

Figure 5. Experimental setup of the sensor for pressure testing under the dynamic temperature.

During the experiment, the sensor was placed in the thermal chamber. A thermocouple was placed near the sensor, the value of which was displayed on the temperature controller. The pressure controller can ensure a uniform distribution of pressure in the pressure vessel. First, at room temperature, we increased the pressure from approximately 0 to $1 \mathrm{MPa}$ at $0.1 \mathrm{MPa}$ steps to verify the voltage response. The pressure was kept for $5 \mathrm{~min}$ at each step, and the corresponding output voltage of the sensor was recorded. Figure 6 shows the fitting curves of the voltage versus pressure during the three pressurization experiments. A linear relationship between the voltage and pressure was observed. The pressure sensitivities of the three tests were $0.1391,0.1390$, and $0.1390 \mathrm{mV} / \mathrm{kPa}$, respectively. For these three repeatable experiments, the repeatability and nonlinear errors are approximately $2.15 \%$ and less than $2.51 \%$, respectively.

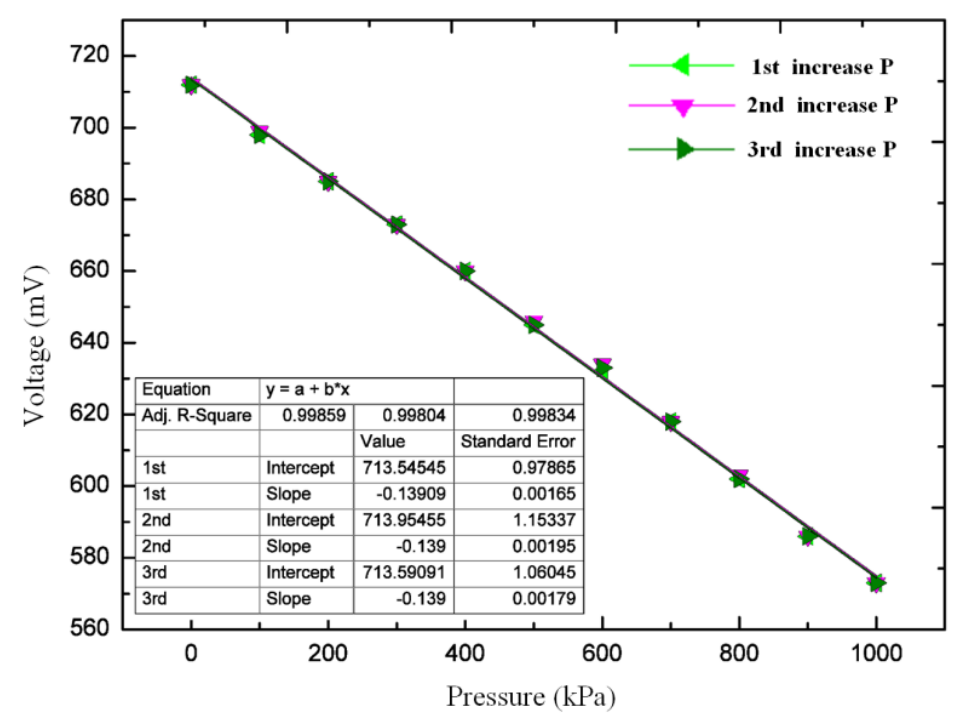

Figure 6. Output voltage versus pressure during three experiments.

To test the temperature performance of the sensor, we monitored the pressure response of the sensor under $20^{\circ} \mathrm{C}, 50{ }^{\circ} \mathrm{C}, 75^{\circ} \mathrm{C}, 100^{\circ} \mathrm{C}, 125^{\circ} \mathrm{C}$, and $150{ }^{\circ} \mathrm{C}$, respectively. Figure 7 shows the response voltage under the different temperatures, and reveals that the response to the pressure at different temperatures is linear. The pressure sensitivities at temperatures of $20^{\circ} \mathrm{C}, 50^{\circ} \mathrm{C}, 75^{\circ} \mathrm{C}, 100{ }^{\circ} \mathrm{C}, 125^{\circ} \mathrm{C}$, and $150^{\circ} \mathrm{C}$, were $0.1387,0.1409,0.1431,0.1452,0.1460$, and $0.1473 \mathrm{mV} / \mathrm{kPa}$, respectively. It was seen that the temperature had a small effect on the sensitivity of the sensor, which may be caused by complex physical mechanisms such as the Young's modulus of the sensitive diaphragm materials changed with 
the temperature. Although the temperature has a certain influence on the sensor, it still showed a good response to the pressure in a temperature environment and achieves good linearity. Figure 8 shows the relationship between the initial sensor voltage with temperature. The experiment results show that the temperature coefficient of the proposed sensor was $0.87 \mathrm{mV} /{ }^{\circ} \mathrm{C}$. When the temperature exceeded $150^{\circ} \mathrm{C}$ at a pressure of $1 \mathrm{MPa}$, the welding part of the sensor was damaged, resulting in the pressure cavity of the sensor not being sealed. Therefore, the sensor can operate at a higher temperature than $150{ }^{\circ} \mathrm{C}$, when the welding process is optimized.

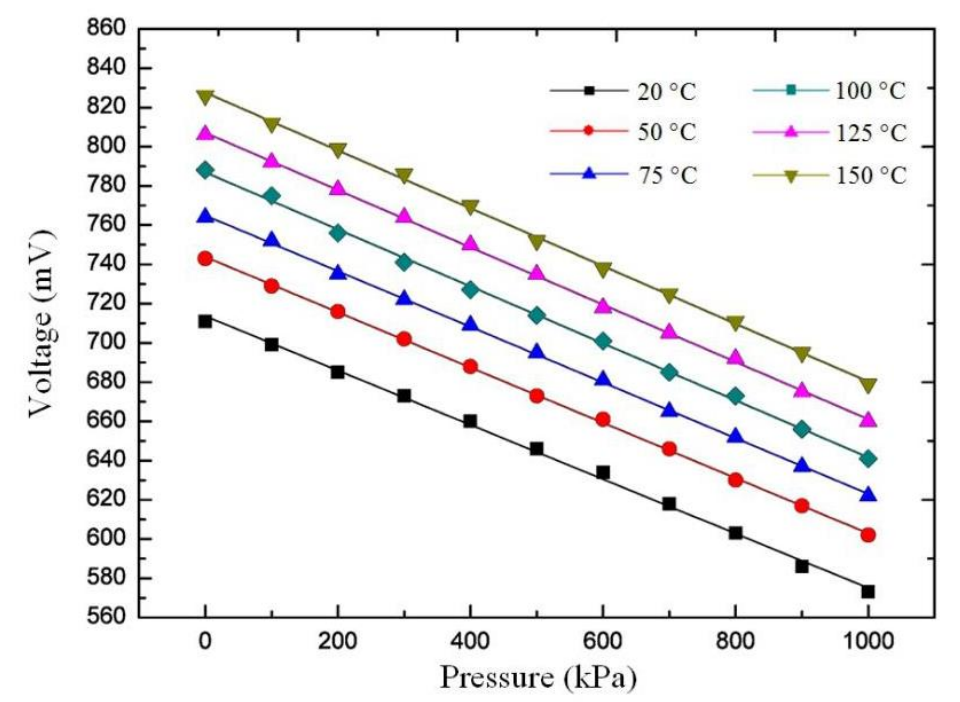

Figure 7. Relationship between the voltage and pressure at different temperatures.

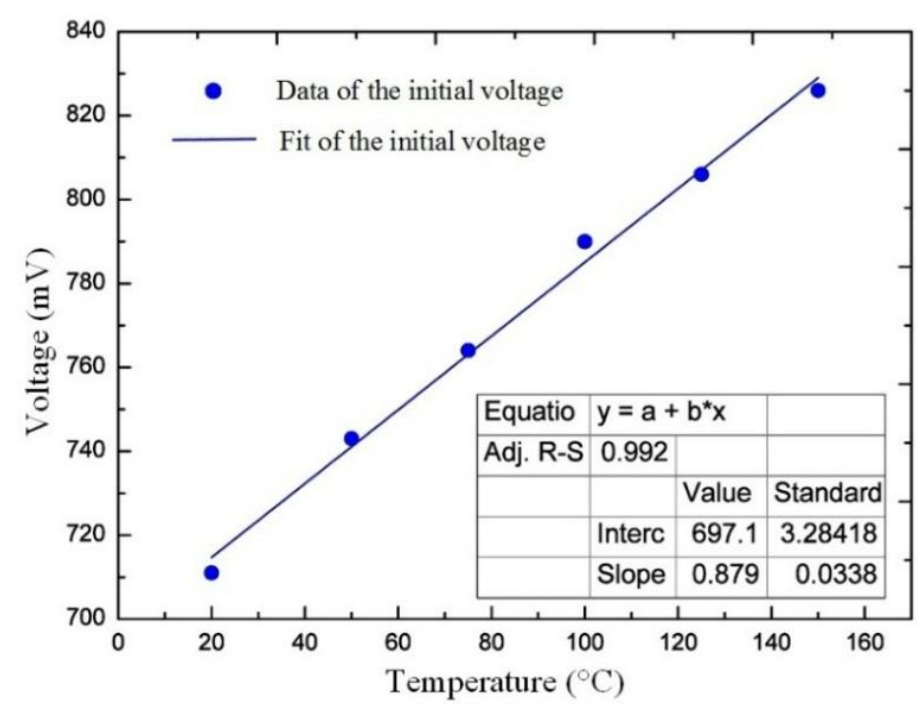

Figure 8. Temperature influence on the initial voltage of the sensor.

To verify the dynamic response of the sensor, a dynamic pressure test system was established, as shown in Figure 9. It consisted of a pressure control system, a sinusoidal pressure generator, a standard piezoelectric sensor, a gas cylinder, a pressure vessel, and a fiber sensing system. Standard piezoelectric sensors were used to monitor pressure changes and feed them back to the pressure control system. During the dynamic experiment, the sensor head was placed in the pressure vessel. The pressure control system controlled the magnitude and frequency of the pressure applied to the sensor. To verify the pressure response of the sensor under dynamic conditions, experiments at $400 \mathrm{~Hz}, 780 \mathrm{~Hz}$, and $1 \mathrm{kHz}$ were performed. Figure 10 shows the output of the sensor under sinusoidal pressure environments at 
room temperature. According to the experiment results, the sensor had a good dynamic response under $400 \mathrm{~Hz}, 780 \mathrm{~Hz}$, and $1 \mathrm{kHz}$ sinusoidal pressure environments.

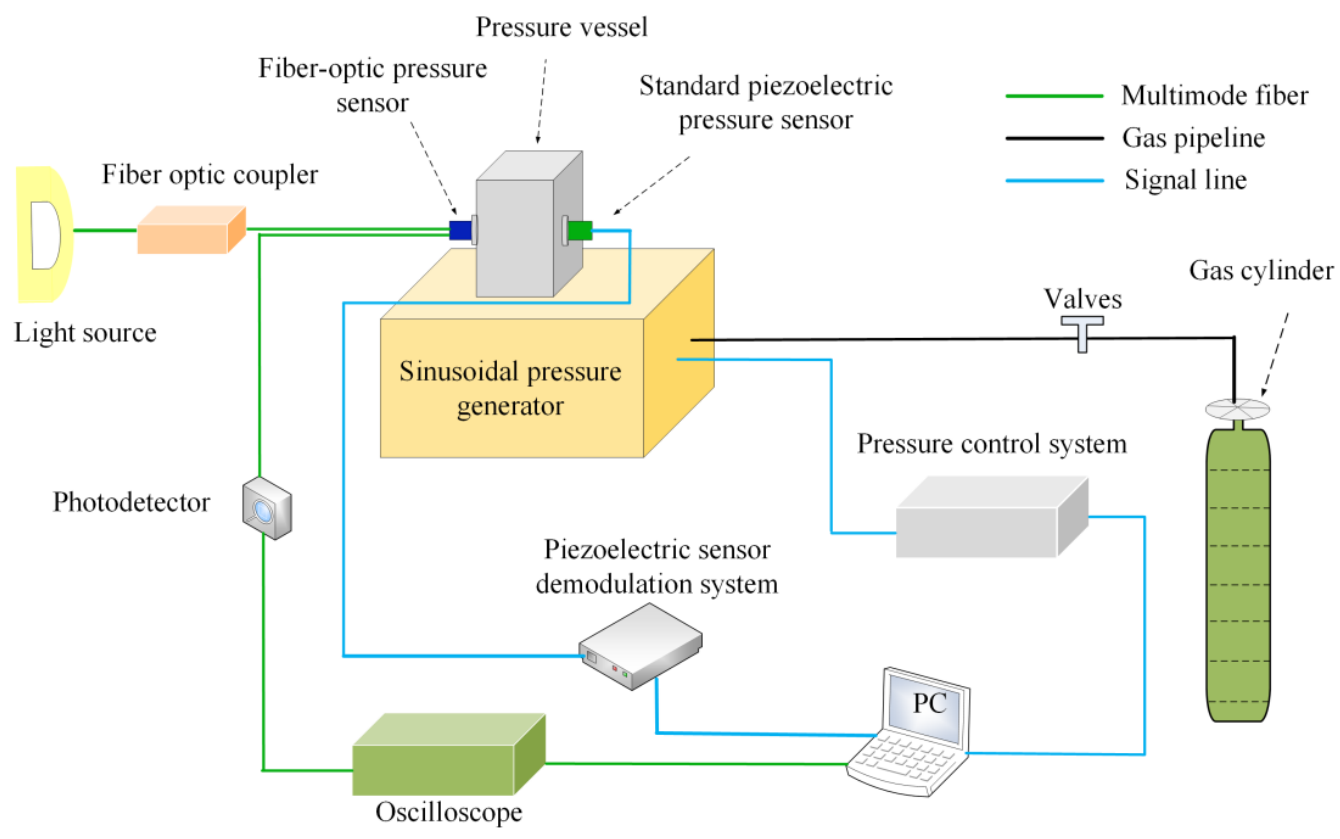

Figure 9. Experimental setup of the dynamic pressure test.

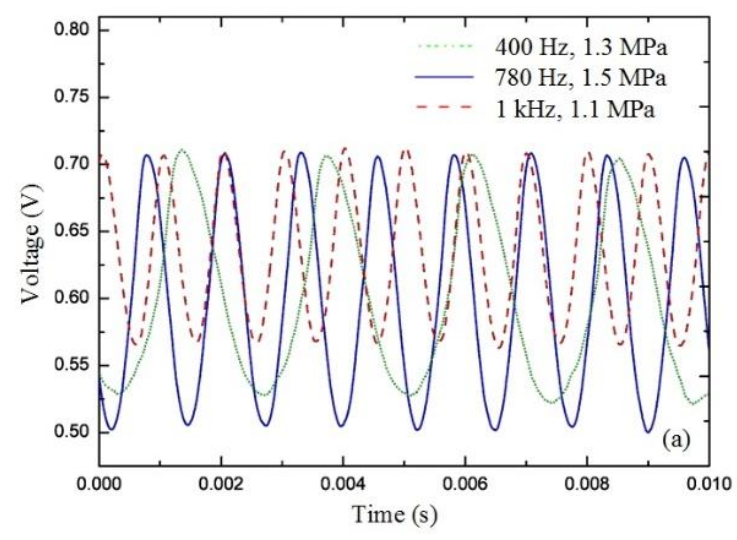

(a)

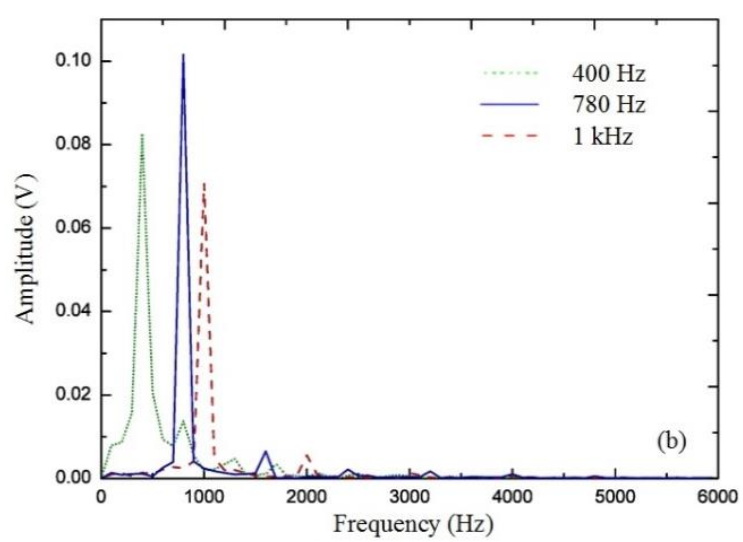

(b)

Figure 10. Output of the sensor: (a) waveform of voltage and (b) fast Fourier transform spectrum of the waveform.

\section{Conclusions}

We proposed and demonstrated a reflective intensity-modulated fiber-optic pressure sensor that can be applied under various pressures from 0 to $1 \mathrm{MPa}$, at room temperatures up to $150{ }^{\circ} \mathrm{C}$. The sensor can also be applied in a dynamic pressure environment and monitor a high-frequency dynamic pressure signal in real time. We used an optical fiber with a microspherical end, which effectively improved the pressure sensitivity of the sensor. The whole sensor was integrated and sealed with a $\mathrm{CO}_{2}$ laser, which is beneficial for improving the sensor performance and avoiding thermal mismatch between the adhesive and the fiber-optic. Moreover, the sensor is fabricated by MEMS techniques, providing the possibility of the batch production. 
Author Contributions: Conceptualization, T.L. and J.X.; Investigation, J.L. and Q.R.; Methodology, P.J. and G.A.; Writing-original draft, N.Z. All authors have read and agree to the published version of the manuscript.

Funding: This research was supported by the National Natural Science Foundation of China under Grant 51935011, the Innovative Research Group Project of National Science Foundation of China under Grant 51821003, the Natural Science Foundation of Shanxi Province of China under Grant 201901D111160, and the Fund for Shanxi "1331 Project" Key Subject Construction.

Conflicts of Interest: The authors declare no conflict of interest.

\section{References}

1. Rosolem, J.B.; Penze, R.S.; Bassan, F.R.; Floridia, C.; Peres, R.; Dini, D.C.; Vasconcelos, D.; Rramos, M.A., Jr. Electroless nickel-plating sealing in fbg pressure sensor for thermoelectric power plant engines applications. J. Light. Technol. 2019, 37, 4791-4798. [CrossRef]

2. Kaczmarek, C. Photonic crystal fiber sensor for impulsive pressure wave measurements. Opt. Lasers Eng. 2019, 122, 23-28. [CrossRef]

3. Alfin, L.; Gino, R.; Ion, S.; Rama, B. Wireless sensing using acoustic signals for measurement of dynamic pressure and temperature in harsh environment. Sens. Rev. 2012, 32, 142-148.

4. Silva, S.; Coelho, L.; Frazão, O. An all-fiber Fabry-Pérot interferometer for pressure sensing in different gaseous environments. Measurement 2014, 47, 418-421. [CrossRef]

5. Gao, L.; Zhu, C.; Li, L.; Zhang, C.-W.; Liu, J.; Yu, H.-D.; Huang, W. All paper-based flexible and wearable piezoresistive pressure sensor. ACS Appl. Mater. Interfaces 2019, 11, 25034-25042. [CrossRef] [PubMed]

6. Akiyama, M.; Morofuji, Y.; Kamohara, T.; Nishikubo, K.; Tsubai, M.; Fukuda, O.; Ueno, N. Flexible piezoelectric pressure sensors using oriented aluminum nitride thin films prepared on polyethylene terephthalate films. J. Appl. Phys. 2006, 100, 114318. [CrossRef]

7. Fischer, R.; Muntjes, J.A.; Mokwa, W. Compensation of the stress dependence of flexible integrated capacitive pressure sensors for biomedical applications. IEEE Sens. 2017, 3, 1-3.

8. Sheeparamatti, B.G.; Balavalad, K.B. Fabrication and characterization of polysilicon-on-insulator (PolySOI) and a-SOI based micro piezoresistive pressure sensor for harsh environment applications. Microsyst. Technol. 2019, 25, 4119-4133. [CrossRef]

9. Lia, X.-J.; Qiu, C.-J.; Deng, Y.-L.; Qu, W.; He, J.-N. An MEMS optical fiber pressure sensor based on a square silicon diaphragm: Numerical simulation and experimental verification. Int. J. Nonlinear Sci. Numer. Simul. 2010, 11, 225-229. [CrossRef]

10. Iwamoto, K.; Kamata, I. Pressure sensor using optical fibers. Appl. Opt. 1990, 29, 375. [CrossRef]

11. Zheng, W.; Xie, J.; Li, Y.; Xu, B.; Kang, J.; Shen, C.; Wang, J.; Jin, Y.; Liu, H.; Ni, K.; et al. A fiber air-gap FabryPérot temperature sensor demodulated by using frequency modulated continuous wave. Opt. Commun. 2014, 324, 234-237. [CrossRef]

12. Zhang, X.; Liu, Y.; Bae, H.; Pang, C.; Yu, M. Phase modulation with micromachined resonant mirrors for low-coherence fiber-tip pressure sensors. Opt. Express 2009, 17, 23965-23974. [CrossRef] [PubMed]

13. Berkovic, G.; Rotter, S.; Shafir, E.; Scandale, W.; Todesco, E. Wavelength-modulated fiber optic sensor for high precision displacement measurement. Rev. Sci. Instrum. 2002, 73, 3687-3691. [CrossRef]

14. Li, X.; Ma, R.; Xia, Y. Magnetic field sensor exploiting light polarization modulation of microfiber with magnetic fluid. J. Light. Technol. 2018, 36, 1620-1625. [CrossRef]

15. Shen, W.; Wu, X.; Meng, H.; Zhang, G.; Huang, X. Long distance fiber-optic displacement sensor based on fiber collimator. Rev. Sci. Instrum. 2010, 81, 123104. [CrossRef]

16. Vallan, A.; Casalicchio, M.L.; Perrone, G. Displacement and acceleration measurements in vibration tests using a fiber optic sensor. IEEE Trans. Instrum. Meas. 2010, 59, 1389-1396. [CrossRef]

17. Perrone, G.; Vallan, A. A low-cost optical sensor for noncontact vibration measurements. IEEE Trans. Instrum. Meas. 2008, 58, 1650-1656. [CrossRef]

18. Feng, K.; Feng, K.; Li, J.; Tan, J. Development of a double fiber probe with a single fiber Bragg grating for dimensional measurement of microholes with high aspect ratios. Opt. Lett. 2014, 39, 2868-2871.

19. Vallan, A.; Casalicchio, M.L.; Olivero, M.; Perrone, G. Two-dimensional displacement sensor based on plastic optical fibers. IEEE Trans. Instrum. Meas. 2013, 62, 1233-1240. [CrossRef] 
20. Guermat, A.; Guessoum, A.; Demagh, N.-E.; Zaboub, M.; Bouhafs, Z. Fibre-optic temperature and pressure sensor based on a deformable concave micro-mirror. Sens. Actuators A Phys. 2018, 270, 205-213. [CrossRef]

21. Song, P.; Ma, Z.; Ma, J.; Yang, L.; Wei, J.; Zhao, Y.; Zhang, M.; Yang, F.; Wang, X. recent progress of miniature MEMS pressure sensors. Micromachines 2020, 11, 56. [CrossRef]

22. Binu, S.; Pillai, V.M.; Chandrasekaran, N. Fibre optic displacement sensor for the measurement of amplitude and frequency of vibration. Opt. Laser Technol. 2007, 39, 1537-1543. [CrossRef]

23. Li, H.; Deng, H.; Zheng, G.; Shan, M.; Zhong, Z.; Liu, B. Reviews on corrugated diaphragms in miniature fiber-optic pressure sensors. Appl. Sci. 2019, 9, 2241. [CrossRef]

24. Gruca, G.; De Man, S.; Slaman, M.; Rector, J.H.; Iannuzzi, D. Ferrule-top micromachined devices: Design, fabrication, performance. Meas. Sci. Technol. 2010, 21, 94033. [CrossRef]

25. Jiang, Y.; Li, J.; Zhou, Z.; Jiang, X.; Zhang, D. Fabrication of all-SiC fiber-optic pressure sensors for hightemperature applications. Sensors 2016, 16, 1660. [CrossRef] [PubMed]

26. Liu, T. Non-destructive residual pressure self-measurement method for the sensing chip of optical Fabry-Perot pressure sensor. Opt. Express 2017, 25, 31937.

27. Bae, H.; Yun, D.; Liu, H.; Olson, U.A.; Yu, M. Hybrid miniature Fabry-Perot sensor with dual optical cavities for simultaneous pressure and temperature measurements. J. Light. Technol. 2014, 32, 1585-1593. [CrossRef]

28. Listewnik, P.; Hirsch, M.; Struk, P.; Weber, M.; Bechelany, M.; Szczerska, M. Preparation and characterization of microsphere $\mathrm{ZnO}$ ALD coating dedicated for the fiber-optic refractive index sensor. Nanomaterials 2019, 9, 306. [CrossRef] [PubMed]

29. Ge, Y.; Wang, M.; Yan, H. Optical MEMS pressure sensor based on a mesa-diaphragm structure. Opt. Express 2008, 16, 21746-21752. [CrossRef]

30. Poeggel, S.; Duraibabu, D.B.; Lacraz, A.; Kalli, K.; Tosi, D.; Leen, G.; Lewis, E. Femtosecond-laser based inscription technique for post Fibre-Bragg grating inscription in an extrinsic Fabry-Perot interferometer pressure sensor. IEEE Sens. J. 2015, 16, 396-402.

31. Hirsch, M.; Listewnik, P.; Struk, P.; Weber, M.; Bechelany, M.; Szczerska, M. ZnO coated fiber optic microsphere sensor for the enhanced refractive index sensing. Sens. Actuators A Phys. 2019, 298, 298. [CrossRef]

32. Lan, T.; Zhang, C.; Fu, S.; Zhu, B.; Tang, M.; Tong, W. Spatial division multiplexing-based reflective intensity-modulated fiber optics displacement sensor. IEEE Photonics J. 2018, 10, 1-7. [CrossRef]

33. Perret, L.; Chassagne, L.; Topcu, S.; Ruaux, P.; Cagneau, B.; Alayli, Y. Fiber optics sensor for sub-nanometric displacement and wide bandwidth systems. Sens. Actuators A Phys. 2011, 165, 189-193. [CrossRef]

34. Harun, S.; Yang, H.Z.; Yasin, M.; Ahmad, H. Theoretical and experimental study on the fiber optic displacement sensor with two receiving fibers. Microw. Opt. Technol. Lett. 2010, 52, 373-375. [CrossRef]

35. Guzowski, B.; Łakomski, M. Realization of fiber optic displacement sensors. Opt. Fiber Technol. 2018, 41, 34-39. [CrossRef]

36. Khiat, A.; Lamarque, F.; Prelle, C.; Pouille, P.; Leester-Schädel, M.; Büttgenbach, S. Long-range displacement mini-sensor with submicrometric resolution. In Proceedings of the 5th IEEE Conference on Sensors, Daegu, Korea, 22-25 October 2006; pp. 283-286.

37. Guzowski, B.; Lisik, Z.; Tosik, G. Realization of optical fibers terminated with ball lenses. Bull. Pol. Acad. Sci. Tech. Sci. 2016, 64, 279-282. [CrossRef]

38. Jia, P.; Liang, H.; Fang, G.; Qian, J.; Feng, F.; Liang, T.; Xiong, J. Batch-producible MEMS fiber-optic Fabry-Perot pressure sensor for high-temperature application. Appl. Opt. 2018, 57, 6687-6692. [CrossRef]

(C) 2020 by the authors. Licensee MDPI, Basel, Switzerland. This article is an open access article distributed under the terms and conditions of the Creative Commons Attribution (CC BY) license (http://creativecommons.org/licenses/by/4.0/). 